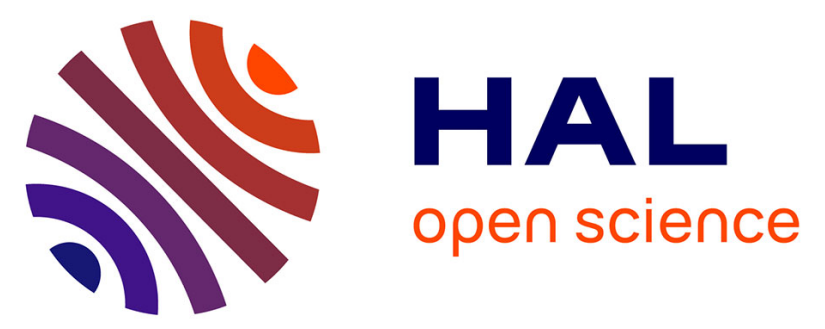

\title{
Prognostic Impact of the Ratio of Acceleration Time to Ejection Time in Patients With Low Gradient Severe Aortic Stenosis and Preserved Ejection Fraction
}

Alexandre Altes, Nicolas Thellier, Yohann Bohbot, Wassima Marsou, Gagandeep Chadha, Camille Binda, Anne Ringle, Amandine Mailliet, Nathalie Marotte, Clemence Riolet, et al.

\section{To cite this version:}

Alexandre Altes, Nicolas Thellier, Yohann Bohbot, Wassima Marsou, Gagandeep Chadha, et al.. Prognostic Impact of the Ratio of Acceleration Time to Ejection Time in Patients With Low Gradient Severe Aortic Stenosis and Preserved Ejection Fraction. American Journal of Cardiology, 2019, 124, pp.1594 - 1600. 10.1016/j.amjcard.2019.07.064 . hal-03488360

\section{HAL Id: hal-03488360 https://hal.science/hal-03488360}

Submitted on 21 Dec 2021

HAL is a multi-disciplinary open access archive for the deposit and dissemination of scientific research documents, whether they are published or not. The documents may come from teaching and research institutions in France or abroad, or from public or private research centers.
L'archive ouverte pluridisciplinaire HAL, est destinée au dépôt et à la diffusion de documents scientifiques de niveau recherche, publiés ou non, émanant des établissements d'enseignement et de recherche français ou étrangers, des laboratoires publics ou privés.

\section{(ㄷ)(1) $(5$}

Distributed under a Creative Commons Attribution - NonCommerciall 4.0 International 


\section{Prognostic Impact of the Ratio of Acceleration Time to Ejection Time in Patients with}

\section{Low Gradient Severe Aortic Stenosis and Preserved Ejection Fraction}

Alexandre Altes ${ }^{\mathrm{a}}$ MD, Nicolas Thellier ${ }^{\mathrm{a}}$ MD, Yohann Bohbot ${ }^{\mathrm{b}, \mathrm{c}}$ MD, Wassima Marsou ${ }^{\mathrm{a}}$ MD, Gagandeep Chadha ${ }^{b}$ MD, Camille Binda ${ }^{a}$ MD, Anne Ringle ${ }^{a}$ MD, Amandine Mailliet a , Nathalie Marotte ${ }^{a}$, Clemence Riolet ${ }^{a}$ MD, Christophe Tribouilloy ${ }^{\mathrm{b}, \mathrm{c}} \mathrm{MD} \mathrm{PhD}$ and Sylvestre Maréchaux ${ }^{\mathrm{a}, \mathrm{c}} \mathrm{MD}$ $\mathrm{PhD}^{* *}$

${ }^{a}$ Université Lille Nord de France, GCS-Groupement des Hôpitaux de l'Institut Catholique de Lille, Laboratoire d'échocardiographie, service de cardiologie Nord, Centre des Valvulopathies, Faculté de Médecine et de Maïeutique, Université Catholique de Lille, Lille, France

${ }^{\mathrm{b}}$ Centre Hospitalier Universitaire d'Amiens, Amiens, France

${ }^{\mathrm{c}}$ Laboratoire UPJCV, Université de Picardie, Amiens, France.

Running head: AT/ET in patients with severe low gradient aortic stenosis

** Corresponding author. Cardiology department, GCS- Groupement des Hôpitaux de l'Institut

Catholique de Lille, Faculté libre de médecine / Université Catholique de Lille, Rue du Grand But, 59160 Lomme, France. Tel: +33 320225057.

E-mail address: Sylvestre.marechaux@yahoo.fr (S. Maréchaux).

\section{Disclosure of interest}

The other authors declare that they have no conflicts of interest concerning this article.

\section{Word count: 2598}




\section{ABSTRACT}

The clinical management of patients with low gradient severe aortic stenosis (LGSAS) and preserved left ventricular ejection fraction (LVEF) remains challenging owing to their heterogeneity. The aim to this study was to evaluate the relationship between an ejection dynamic parameter linked to AS severity and outcome, the ratio of acceleration time (AT) to ejection time (ET), in a cohort of patients with LG-SAS and preserved LVEF. 356 patients with LG-AS (defined by AVA $\leq 1 \mathrm{~cm}^{2}$ and/or $\mathrm{AVAi} \leq 0.6 \mathrm{~cm}^{2} / \mathrm{m}^{2}$ and mean aortic pressure gradient $<40 \mathrm{mmHg}$ ) and preserved $\mathrm{LVEF} \geq 50 \%$ were studied. The relationship between AT/ET and all-cause and cardiac mortality during follow-up was studied. Median follow-up was 41 months (interquartile range, 35-47 months). Median AT/ET was 0.32 (IQR, 0.290.36). The 5-year estimates of all-cause and cardiac mortality were respectively $57 \pm 7 \%$, $36 \pm 7 \%$ for patients with AT/ET > 0.36 versus $43 \pm 4 \%, 16 \pm 3 \%$ for patients with AT/ET $\leq 0.36$ ( $\mathrm{p}=0.024$ and $\mathrm{p}<0.001$, respectively). After adjustment on known predictors of outcome including aortic valve replacement (AVR) used as a time-dependent covariate, there was a significant increase in all-cause mortality risk for patients with AT/ET $>0.36$ (adjusted HR 2.04 [95\% CI, 1.32-3.13]; $\mathrm{p}=0.001$ ) and cardiac mortality risk (adjusted HR 2.89 [95\% CI, 1.54-5.43]) compared with patients with AT/ET $\leq 0.36$. The association of AT/ET $>0.36$ and all-cause or cardiac mortality risk was consistent in subgroups of patients with LG-SAS and preserved EF. In conclusion, an AT/ET ratio of more than 0.36 is an independent predictor of mortality in patients with LG-SAS and preserved EF.

Keywords : aortic stenosis, low gradient, ejection dynamics parameters, echocardiography, outcome 


\section{INTRODUCTION}

According to current guidelines, severe aortic stenosis (SAS) is classically defined by a transvalvular mean pressure gradient (MPG) $>40 \mathrm{~mm} \mathrm{Hg}$ or peak aortic jet velocity $>4 \mathrm{~m} / \mathrm{s}$ 1, and/or an aortic valve area (AVA) $\leq 1.0 \mathrm{~cm}^{2}$ or an AVA indexed to body surface area (AVAi) $\leq 0.6 \mathrm{~cm}^{2} / \mathrm{m}^{2}$. However, up to $40 \%$ of patients with severe AS show discrepancies in their Doppler-echocardiographic AS parameters, the most common of which being the association of a reduced AVA but a low transvalvular gradient $(<40 \mathrm{mmHg})^{2}$. In this subgroup of patients with "low gradient severe aortic stenosis" (LG-SAS), it is still a matter of debate to determine who should be considered for aortic valve replacement (AVR) and who should be treated conservatively ${ }^{3}$. The ratio of acceleration time (AT) to ejection time (ET) is a simple and reproducible parameter which may be used to assess native AS severity ${ }^{4}$, but its prognostic implications have not been specifically evaluated in patients with LG-SAS and preserved left ventricular ejection fraction (LVEF). The present study addressed this issue.

\section{METHODS}

Between 2012 and 2018, 356 patients $\geq 18$ years of age diagnosed with severe AS [defined as AVA $\leq 1 \mathrm{~cm}^{2}$ and/or AVA normalized to body surface area (BSA) $\leq 0.6 \mathrm{~cm}^{2} / \mathrm{m}^{2}$ ], a low transaortic gradient (defined as mean aortic pressure gradient (MPG) $<40 \mathrm{mmHg}$ ) and preserved LVEF $\geq 50 \%$ in the echocardiography laboratories of two tertiary hospitals in France (Lille and Amiens) were prospectively included in the present ancillary study from a larger registry. We excluded: (i) >mild aortic and/or mitral regurgitation; (ii) prosthetic valves, congenital heart disease, supravalvular or subvalvular AS, or dynamic LV outflow tract obstruction; (iii) mitral stenosis; and (iv) patients who refused to participate in the study. Clinical and demographic baseline characteristics were collected. The Charlson comorbidity 
index, summating the patient's individual comorbidities, was calculated. ${ }^{5}$ Coronary artery disease was defined by the presence of documented history of acute coronary syndromes, coronary artery disease previously confirmed by coronary angiography (reduction of normal diameter $\geq 50 \%$ in the left main coronary artery and $\geq 70 \%$ in the right coronary artery, left anterior descending coronary artery, left anterior descending coronary artery, and circumflex coronary artery), or history of coronary revascularization. The study had been approved by an independent ethic committee and was conducted in accordance with institutional policies, national legal requirements, and the revised Declaration of Helsinki. Authorization for research participation was obtained for all patients.

All patients underwent a comprehensive Doppler-echocardiography study, using commercially available ultrasound systems by experienced echocardiographers. Aortic flow was recorded using continuous-wave Doppler, by imaging and non-imaging transducers, systematically in several acoustic windows (apical 5-chamber, right parasternal, suprasternal, epigastric). The highest aortic velocity was used to calculate aortic time-velocity integral and mean pressure gradient (MPG). As recommended by current guidelines ${ }^{6}$, wall (high-pass) filters are set at a high level and gain is decreased to optimize identification of the velocity curve from the spectrogram envelope. LV stroke volume (LV-SV) was calculated by multiplying the LV outflow tract area with the LV outflow tract time-velocity integral obtained by pulsed Doppler in the apical 5-chamber view. The LV outflow tract diameter was measured in zoomed parasternal long-axis views in early systole at the level of aortic cusp insertion (inner-to-inner edge). Aortic valve area (AVA) was calculated using the continuity equation. AVA and LV-SV were indexed to BSA. Low flow was considered if LV-SV was < $35 \mathrm{~mL} / \mathrm{m}^{2}{ }^{7}$ Conventional echocardiographic measurements were performed according to current EACVI/ASE guidelines. ${ }^{8}$ AT was defined as time from the start to the peak of flow 
through the valve by continuous-wave Doppler. ET was defined from aortic valve opening to aortic valve closure (Figure 1). Continuous-wave Doppler recordings were performed at a sweep speed of $100 \mathrm{~mm} / \mathrm{sec}$. The AT/ET ratio was then calculated. Interobserver variability of AT/ET ratio has been previously reported in our institution, with an Intra Class Correlation coefficient at $0.90 \mathrm{CI} 95 \% 0.78-0.96$ and a coefficient of variation=7.3\%. ${ }^{9}$ When patients were in sinus rhythm, three cardiac cycles were averaged for all measures. For patients in atrial fibrillation, five cardiac cycles were averaged. Echocardiograms were stored in Digital Imaging and Communications in Medicine format to allow subsequent offline analysis.

After the initial medical management, treatment was conservative or surgical, as deemed appropriate by the patient's personal physician. The majority of patients were followed by clinical consultation and echocardiography in the outpatient clinics of the 2 tertiary centres. The others were followed in public hospitals or private practices by referring cardiologists working together with the tertiary centres. Information on follow-up was retrospectively obtained. Events were ascertained by direct patient interview and clinical examination and/or by repeated follow-up letters, questionnaires, and telephone calls to physicians, patients, and (if necessary) next of kin. Medical reports and death certificates were consulted for attribution of causes of death. Eighty-four percent of patients were followed for at least 2 years or until death. The outcome variable of the study was all-cause mortality. Cardiac mortality was also studied. Clinical decisions regarding medical management and referral for surgery were made by the heart team with the approval of the patient's cardiologist in accordance with current practice guidelines.

The study population was divided in two groups according to AT/ET threshold of 0.36 as previously reported. The relationship between baseline continuous variables and the 2 groups was explored using an unpaired two-sided Student's t-test (for normally distributed 
variables) or Mann-Whitney U test (for non-normally distributed variables). Pearson chisquare test or Fisher exact test was used to examine the association between the two groups and baseline categorical variables.

Median follow-up time was obtained using the reverse Kaplan-Meier method. Event rates +/- SEs of the overall population and of the two groups were estimated according to the Kaplan-Meier method and compared using log-rank tests. Univariate and multivariate analyses of time to events were performed using Cox proportional-hazards models. We did not use model building techniques; covariates were entered in the models which were considered of potential prognostic impact on an epidemiologic basis. Models were adjusted for age, gender, Charlson comorbidity index (not including age), hypertension, coronary artery disease, atrial fibrillation, symptoms (New York Heart Association Class III-IV dyspnea, angina, or syncope), LVEF, low flow, aortic valve area, and aortic valve replacement (AVR). The effect of AVR on outcome was analyzed as a time-dependent covariable using the entire follow-up. The proportional hazards assumption was confirmed using statistics and graphs based on the Schoenfeld residuals. For continuous variables, the assumption of linearity was assessed by plotting residuals against independent variables. To evaluate whether AT/ET > 0.36 provides incremental prognostic value over clinical and echocardiographic variables, the differences between models were tested by calculating the overall difference in $-2 \log$ likelihood $\chi 2$ between models. We conducted subgroup analyses to determine the homogeneity of the association of AT/ET ratio and all-cause mortality. First, we estimated the effect of AT/ET on all-cause mortality in each subgroup using a Cox univariate model and then formally tested for first-order interactions entering interaction terms, separately for each subgroup. All p-values are the results of two-tailed tests. For all analyses, a $\mathrm{P}$ value of $<0.05$ was considered statically significant. Data were analyzed with $\mathrm{R}$ 
version 3.4.4 (R Foundation for Statistical Computing, Vienna, Austria) and SPSS version 20.0 (IBM, Amonk, New York).

\section{RESULTS}

Three hundred and fifty-six patients were enrolled in the present study. Patient's clinical characteristics, overall and according to AT/ET threshold of 0.36 are detailed in Table 1. Median AT/ET was 0.32 (IQR, 0.29-0.36). Seventy-five patients (21\%) had a value of AT/ET > 0.36. Patients with AT/ET > 0.36 were similar to patients with an AT/ET $\leq 0.36$ in terms of clinical profile (Table 1). The echocardiographic characteristics of the study population and according to AT/ET $\leq$ or $>0.36$ are detailed in Table 2. Briefly, patients with AT/ET > 0.36 had lower AVA, AVAi, higher peak aortic jet velocity and transaortic mean pressure gradient. They had a higher LV mass index but showed no other difference for LV function, volumes, or cardiac output.

During a median follow-up time of 41 months (interquartile range, 35-47 months), 135 patients died, 53 of them from cardiac causes. AVR was performed in 116 patients (surgical AVR in 72 patients, and TAVR in 44 patients), Among patients who underwent surgical AVR, 22 patients had at least one associated coronary artery bypass graft at the time of surgery. Overall, the 1-, 3- and 5-year estimates of all-cause mortality were 19+/-2\%, 35+/$3 \%, 47+/-3 \%$. The 5-year estimate of all-cause mortality was $57+/-7 \%$ for patients with AT/ET $>0.36$ and $43+/-4 \%$ for patients with AT/ET $\leq 0.36(\mathrm{p}=0.024$, figure 2A). Overall, the 1-, 3- and 5-year estimates of cardiac mortality were $19+/-2 \%, 14+/-2 \%, 21+/-3 \%$. The 5 -year estimate of cardiac mortality was $36+/-7 \%$ for patients with AT/ET $>0.36$ and $16+/-3 \%$ for patients with $\mathrm{AT} / \mathrm{ET} \leq 0.36(\mathrm{p}<0.001$, figure $\mathbf{2 B})$. When patients were analyzed under medical treatment (i.e censored at the time of AVR if performed), AT/ET > 0.36 remained 
significantly associated with an increased risk of all-cause and cardiac mortality (log-rank $\mathrm{p}=0.009$ and $\mathrm{p}=0.002$, respectively).

After adjustment for covariates of prognostic importance, AVA, low flow status, and AVR as a time-dependent covariable, the association between AT/ET > 0.36 and all-cause mortality remained unchanged (adjusted HR 2.04 [95\% CI, 1.32-3.13]; p=0.001, Table 3, Figure 3A). When replacing AT/ET $>0.36$ by quartiles of AT/ET (AT/ET $<0.29,0.29$ to $0.32,0.32$ to 0.36 and $>0.36$ ) in this multivariate model, only patients with an AT/ET > 0.36 had a significant increased risk of all-cause mortality (adjusted HR 2.44 [95\% CI, 1.44-4.02]; $\mathrm{p}<0.001)$ compared to patients in the first quartile (AT/ET $<0.29$ ). Adjusted all-cause mortality was similar in the other quartiles (AT/ET 0.29 to 0.32 and 0.32 to 0.36 ) compared with patients in the first quartile ( $\mathrm{p}=0.204$ and $\mathrm{p}=0.369$ respectively). Replacing AVA by MPG or aortic peak velocity in this multivariate model did not alter the strength of the relationship between AT/ET > 0.36 and all-cause mortality (adjusted HR 1.92 [95\% CI, 1.262.92]; $p=0.002$, and adjusted HR 1.93 [95\% CI, 1.27-2.94]; $p=0.002$, respectively). AT/ET > 0.36 provided incremental prognostic value over clinical and echocardiographic variables (Figure 4). Similar results were found for cardiac mortality (adjusted HR 2.89 [95\% CI, 1.545.43], Table 3, Figure 3B).

The association of AT/ET > 0.36 and all-cause mortality risk was consistent in subgroups of patients with LG-AS (Figure 5). There were no significant interactions between AT/ET $>0.36$ and any of the subgroups.

\section{DISCUSSION}

In the present study based on patients with low gradient SAS and preserved LVEF managed in clinical routine practice, we observed that an increase of AT/ET $>0.36$ is associated with worse outcome. Accordingly, patients with AT/ET $>0.36$ experienced a 
significant increase of the risk of all-cause and cardiac mortality during follow up after adjustment on known predictors of outcome including AVR used as a time-dependent covariate compared with patients with AT/ET $\leq 0.36$. Hence, these results demonstrate the interest of assessing AT/ET in routine echocardiographic practice to identify patients with a poor outcome who may derive benefit from AVR among the challenging group of patients with LG-SAS and preserved EF.

Management of patients with LG-SAS and preserved EF still represents a challenge mainly due to the heterogeneity of this specific population ${ }^{10}$. Among these patients, the identification of those who would take benefit of surgical or percutaneous AVR is of particular importance ${ }^{11-13}$. Considering the currently available published data, it becomes clear that among patients with LG-AS and preserved EF, careful evaluation is needed to differentiate patients with "true-severe" AS that lead to discuss AVR from patient with pseudo-severe AS, actually moderate AS that should be managed conservatively ${ }^{14}$. Use of multi-modality imaging permits to improve risk stratification ${ }^{15,16}$. Measurement of the degree of aortic valve calcification (AVC) using multi-detector computed tomography (MDCT) is an accurate, flow-independent method to assess AS severity including LG-AS ${ }^{17}$. Stroke volume assessment by MDCT and Doppler data may be considered to avoid misclassifications in patients with LG-SAS due to the elliptical shape of the LVOT ${ }^{18}$. Recent data have suggested that calculation of projected AVA derived from preload or dobutamine/exercise stress echocardiography may be useful to predict adverse events in patients with LG-AS and preserved EF ${ }^{19,20}$. However, access to multi-modality imaging is not widely open and calculation of projected AVA may be cumbersome in daily clinical practice. Beyond conventional indices of AS severity, new echocardiographic parameters, easy-to-measure and reproducible, are needed to guide routine practice. 
The AT/ET ratio reflecting ejection dynamics through the valve, is a convenient, angle-independent, and reproducible parameter. Landmark AS studies introduced before the emergence of two-dimensional echocardiography have shown that moderate AS has fast upstroke and slow down-stroke; in contrast, severe calcified AS has slower up-stroke resulting in an aortic flow with rounded contour. Rapid early-systolic opening of normal the aortic valve on Doppler spectrograms is replaced by a slow end-systolic opening of the stenotic aortic valve ${ }^{21}$. However, although guidelines suggest that the aortic waveform shape could be useful to assess severity of native AS, until recently a few attention had been given to ejection dynamics parameters in the setting of these patients. We recently shown that prolonged AT/ET is a valuable parameter to predict mortality in unselected patients with at least moderate AS, with a prognostic cut-off value of $0.36^{9}$. Sato et al. have recently shown that prolonged time between left ventricular and aortic systolic pressure peaks measured by left cardiac catheterization is associated with SAS according to aortic valve calcification scoring, including a subgroup of patients with LG-SAS ${ }^{22}$. To the best of our knowledge, no study has specifically studied the relationship between AT/ET ratio and outcome in patients with LGSAS and preserved EF. In the present study, we observed that patients with LG-SAS and an AT/ET > 0.36 had a 2 fold increase of all-cause mortality and nearly 3 fold increase of cardiac mortality compared to patients with AT/ET $\leq 0.36$. Interestingly, the AT/ET ratio performed well in subgroups of patients with LG-SAS and preserved EF, with no interaction between its prognostic power and sex, low flow status (defined by a stroke volume index $<35 \mathrm{~mL} / \mathrm{m}^{2}$ ), presence of AS-related symptoms, hypertension or atrial fibrillation.

AT/ET measurement is probably less angle-dependent than Doppler velocities. Hatle et al demonstrated that AT/ET well correlates with peak pressure gradient obtained by catheterism. ${ }^{23}$ Interestingly, in Hatle's report, some AS patients had an underestimation of 
peak pressure gradient compared with cardiac catheterism, but had a prolonged AT/ET ratio, suggesting that AT/ET may be effectively measured if the maximal velocity cannot be obtained by Doppler. However, as AS assessment primarily relies on the highest aortic jet velocity and gradients, we recommend to measure AT/ET on the corresponding acoustic window.

Our study has several limitations. Whereas echocardiograms were prospectively collected, follow-up data were obtained retrospectively; hence, our study presents inherent limitations of this type of analysis. The specific indications for surgery during follow-up were not collected in our database. However, diagnosis and follow-up were performed by cardiologists with expertise in valvular disease, and the surgical decisions were made by the heart team with the approval of the patients' physicians in accordance with current practice guidelines. Although it has been previously shown that assessing aortic valve calcification by multidetector computed tomography was of interest to stratify risk of patients with AS, this information was not available in our study.

In conclusion, our study shows that AT/ET ratio is independently predictive of allcause and cardiac mortality in patients with LG-SAS and preserved left ventricular ejection fraction and permits to identify a high risk subgroup of patients with a very poor outcome. 


\section{Figure legends}

Figure 1. Systolic time interval measurement on a continuous-wave Doppler recording of transaortic flow.

Figure 2. Kaplan Meier estimates for all-cause (A). and cardiac (B) mortality according to $\mathrm{AT} / \mathrm{ET}>$ or $\leq 0.36$

Figure 3. Cumulative hazard of all-cause (C) and cardiac (D) mortality according to AT/ET > or $\leq 0.36$

Figure 4. Incremental prognostic value of AT/ET > 0.36 over clinical and echocardiographic data.

Figure 5. Hazard ratio and $95 \%$ confidence interval for risk of all-cause mortality associated with AT/ET > 0.36 in subgroups of patients with LG-AS and preserved EF 
1. Baumgartner H, Falk V, Bax JJ, De Bonis M, Hamm C, Holm PJ, Iung B, Lancellotti P, Lansac E, Rodriguez Munoz D, Rosenhek R, Sjogren J, Tornos Mas P, Vahanian A, Walther T, Wendler O, Windecker S, Zamorano JL, Group ESCSD. 2017 ESC/EACTS Guidelines for the management of valvular heart disease. Eur Heart J 2017;38:2739-2791.

2. Clavel MA, Burwash IG, Pibarot P. Cardiac Imaging for Assessing Low-Gradient Severe Aortic Stenosis. JACC Cardiovasc Imaging 2017;10:185-202.

3. Reddy YNV, Nishimura RA. Paradox of Low-Gradient Aortic Stenosis. Circulation 2019;139:2195-2197.

4. Gamaza-Chulian S, Camacho-Freire S, Toro-Cebada R, Giraldez-Valpuesta A, BenezetMazuecos J, Vargas-Machuca JC. Ratio of Acceleration Time to Ejection Time for Assessing Aortic Stenosis Severity. Echocardiography 2015;32:1754-1761.

5. Charlson ME, Pompei P, Ales KL, MacKenzie CR. A new method of classifying prognostic comorbidity in longitudinal studies: development and validation. J Chronic Dis 1987;40:373-383.

6. Baumgartner H, Hung J, Bermejo J, Chambers JB, Edvardsen T, Goldstein S, Lancellotti P, LeFevre M, Miller F, Jr., Otto CM. Recommendations on the Echocardiographic Assessment of Aortic Valve Stenosis: A Focused Update from the European Association of Cardiovascular Imaging and the American Society of Echocardiography. J Am Soc Echocardiogr 2017;30:372-392.

7. Hachicha Z, Dumesnil J, Bogaty P, Pibarot P. Paradoxical low-flow, low-gradient severe aortic stenosis despite preserved ejection fraction is associated with higher afterload and reduced survival. Circulation 2007;115:2856.

8. Lang RM, Badano LP, Mor-Avi V, Afilalo J, Armstrong A, Ernande L, Flachskampf FA, Foster E, Goldstein SA, Kuznetsova T, Lancellotti P, Muraru D, Picard MH, Rietzschel ER, Rudski L, Spencer KT, Tsang W, Voigt JU. Recommendations for cardiac chamber 
quantification by echocardiography in adults: an update from the American Society of Echocardiography and the European Association of Cardiovascular Imaging. J Am Soc Echocardiogr 2015;28:1-39 e14.

9. Ringle Griguer A, Tribouilloy C, Truffier A, Castel AL, Delelis F, Levy F, Vincentelli A, Bohbot Y, Marechaux S. Clinical Significance of Ejection Dynamics Parameters in Patients with Aortic Stenosis: An Outcome Study. J Am Soc Echocardiogr 2018;31:551-560.e552.

10. Baumgartner H. Low Gradient Aortic Stenosis: Who Benefits From Intervention? JACC Cardiovasc Imaging 2019;12:81-83.

11. Mo Y, Van Camp G, Di Gioia G, Barbato E, Ondrus T, Casselman F, Vanderheyden M, De Bruyne B, Bartunek J, Penicka M. Aortic valve replacement improves survival in severe aortic stenosis with gradient-area mismatch. Eur J Cardiothorac Surg 2018;53:569-575.

12. Osman M, Ghaffar YA, Foster T, Osman K, Alqahtani F, Shah K, Kheiri B, Alkhouli M. Meta-Analysis of Outcomes of Transcatheter Aortic Valve Implantation Among Patients With Low Gradient Severe Aortic Stenosis. Am J Cardiol 2019;124:423-429.

13. Fischer-Rasokat U, Renker M, Liebetrau C, van Linden A, Arsalan M, Weferling M, Rolf A, Doss M, Mollmann H, Walther T, Hamm CW, Kim WK. 1-Year Survival After TAVR of Patients With Low-Flow, Low-Gradient and High-Gradient Aortic Valve Stenosis in Matched Study Populations. JACC Cardiovasc Interv 2019;12:752-763.

14. Gonzalez Gomez A, Fernandez-Golfin C, Monteagudo JM, Izurieta C, Hinojar R, Garcia A, Casas E, Jimenez-Nacher JJ, Moya JL, Ruiz S, Zamorano JL. Severe aortic stenosis patients with preserved ejection fraction according to flow and gradient classification: Prevalence and outcomes. Int J Cardiol 2017;248:211-215.

15. Messika-Zeitoun D, Oh JK, Topilsky Y, Burwash IG, Michelena HI, Enriquez-Sarano M. Low-Gradient Aortic Stenosis: Solving the Conundrum Using Multi-Modality Imaging. Prog Cardiovasc Dis 2018;61:416-422. 
16. Delgado V, Clavel MA, Hahn RT, Gillam L, Bax J, Sengupta PP, Pibarot P. How Do We Reconcile Echocardiography, Computed Tomography, and Hybrid Imaging in Assessing Discordant Grading of Aortic Stenosis Severity? JACC Cardiovasc Imaging 2019;12:267282.

17. Pawade T, Clavel MA, Tribouilloy C, Dreyfus J, Mathieu T, Tastet L, Renard C, Gun M, Jenkins WSA, Macron L, Sechrist JW, Lacomis JM, Nguyen V, Galian Gay L, Cuellar Calabria H, Ntalas I, Cartlidge TRG, Prendergast B, Rajani R, Evangelista A, Cavalcante JL, Newby DE, Pibarot P, Messika Zeitoun D, Dweck MR. Computed Tomography Aortic Valve Calcium Scoring in Patients With Aortic Stenosis. Circ Cardiovasc Imaging 2018;11:e007146.

18. Stahli BE, Stadler T, Holy EW, Nguyen-Kim TDL, Hoffelner L, Erhart L, Obeid S, Niemann M, Jenni R, Hamada S, Manka R, Luscher TF, Maisano F, Nietlispach F, Frauenfelder T, Tanner FC. Impact of stroke volume assessment by integrating multi-detector computed tomography and Doppler data on the classification of aortic stenosis. Int J Cardiol 2017;246:80-86.

19. Kusunose K, Yamada H, Nishio S, Torii Y, Hirata Y, Seno H, Saijo Y, Ise T, Yamaguchi K, Yagi S, Soeki T, Wakatsuki T, Sata M. Preload Stress Echocardiography Predicts Outcomes in Patients With Preserved Ejection Fraction and Low-Gradient Aortic Stenosis. Circ Cardiovasc Imaging 2017;10.

20. Clavel MA, Ennezat PV, Marechaux S, Dumesnil JG, Capoulade R, Hachicha Z, Mathieu P, Bellouin A, Bergeron S, Meimoun P, Arsenault M, Le Tourneau T, Pasquet A, Couture C, Pibarot P. Stress echocardiography to assess stenosis severity and predict outcome in patients with paradoxical low-flow, low-gradient aortic stenosis and preserved LVEF. JACC Cardiovasc Imaging 2013;6:175-183. 
21. Bermejo J, Antoranz JC, Garcia-Fernandez MA, Moreno MM, Delcan JL. Flow dynamics of stenotic aortic valves assessed by signal processing of Doppler spectrograms. Am J Cardiol 2000;85:611-617.

22. Sato K, Kumar A, Jobanputra Y, Betancor J, Halane M, George R, Menon V, Krishnaswamy A, Tuzcu EM, Harb S, Jaber WA, Mick S, Svensson LG, Kapadia SR. Association of Time Between Left Ventricular and Aortic Systolic Pressure Peaks With Severity of Aortic Stenosis and Calcification of Aortic Valve. JAMA Cardiol 2019;4:549-555. 23. Hatle L, Angelsen BA, Tromsdal A. Non-invasive assessment of aortic stenosis by Doppler ultrasound. Br Heart J 1980;43:284-292. 


\section{$A T=108 \mathrm{~ms}$ $\mathrm{ET}=300 \mathrm{~ms}$ 10. AT $/ E T=108 / 300=0.36$}

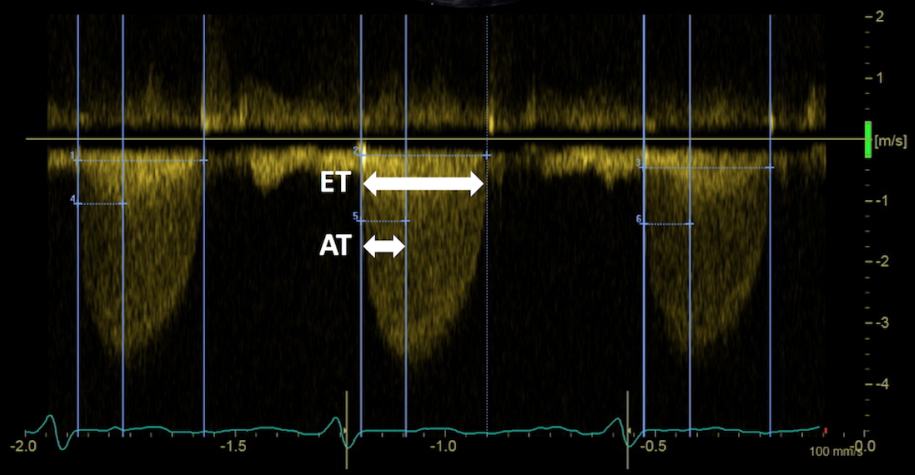




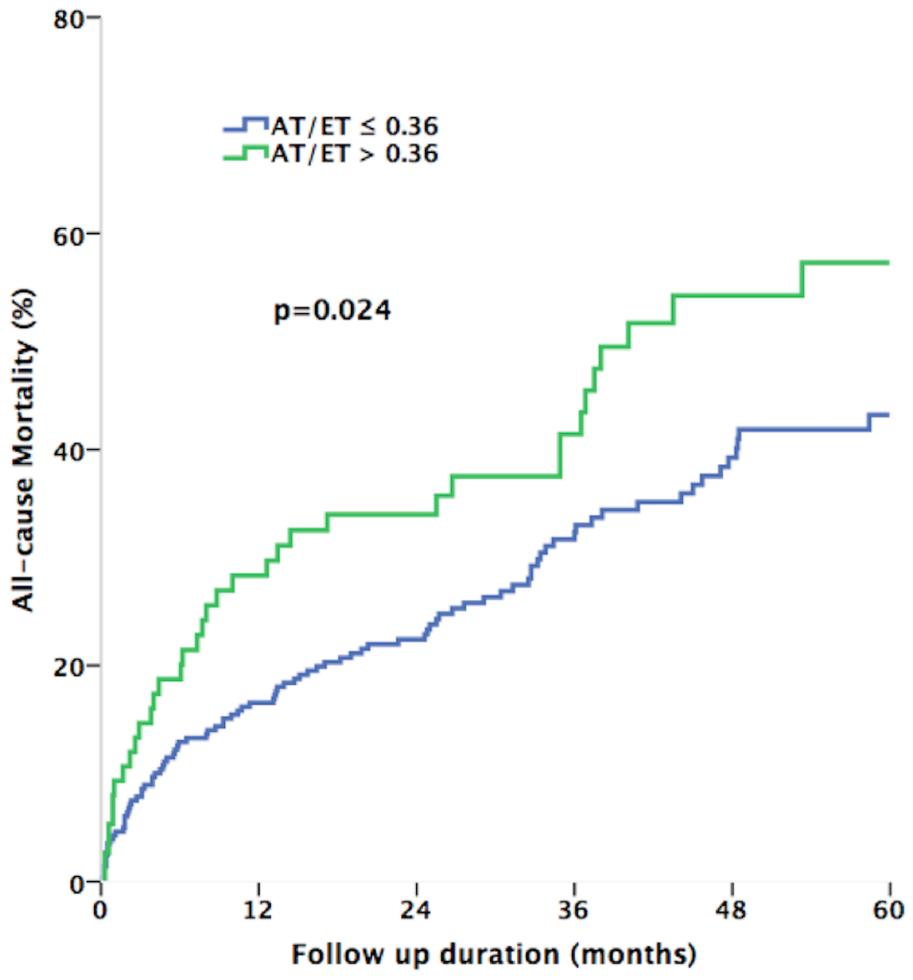

Number at risk

$\begin{array}{cccccc}281 & 229 & 171 & 104 & 71 & 39 \\ 75 & 52 & 40 & 29 & 16 & 10\end{array}$




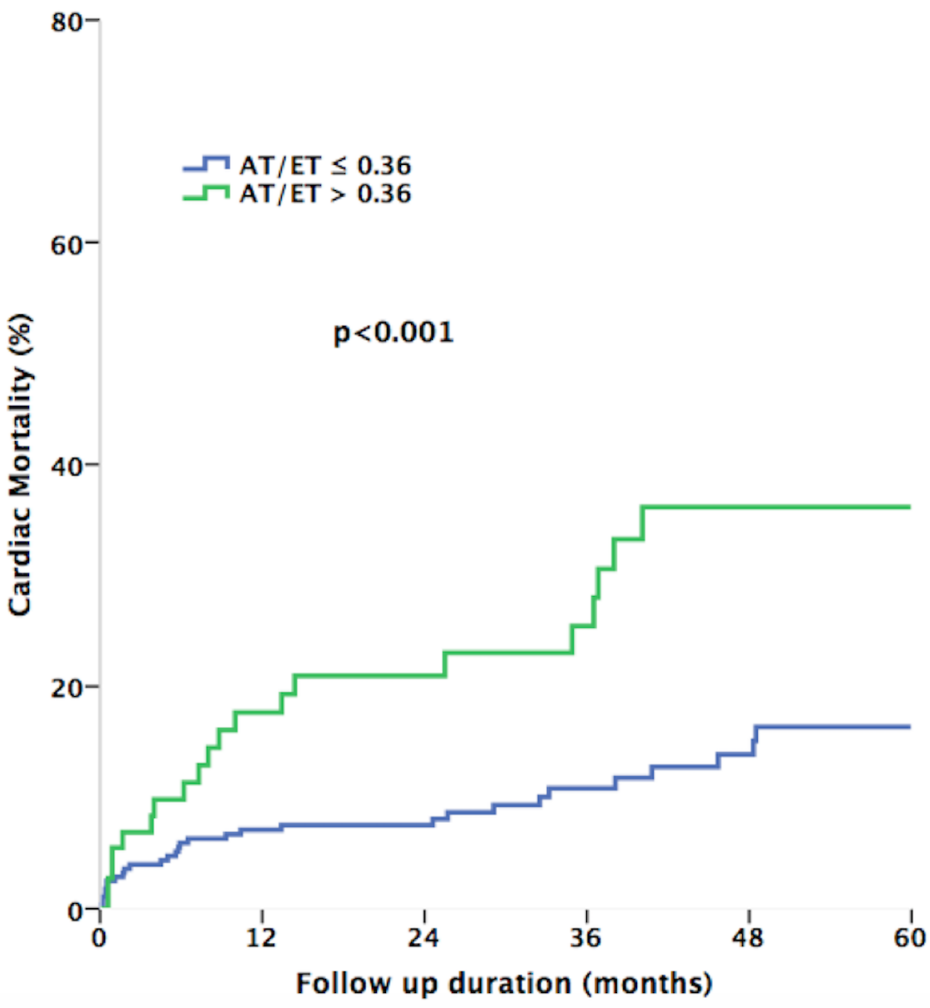

Number at risk

$\begin{array}{cccccc}281 & 229 & 171 & 104 & 71 & 39 \\ 75 & 52 & 40 & 29 & 16 & 10\end{array}$


$80^{-}$

$\neg$ AT/ET $\leq 0.36$

$\neg$ AT/ET > 0.36

60-

$$
\mathrm{p}=0.001 \mathrm{HR}=2.04 \mathrm{IC} 95 \%(1.32-3.13)
$$

$40^{-}$

总

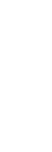

$20^{-}$

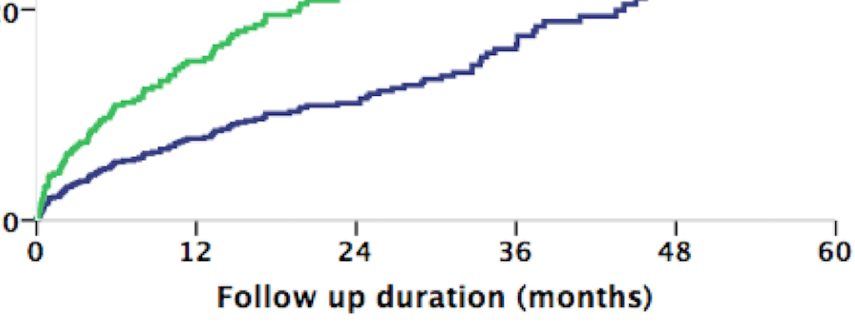




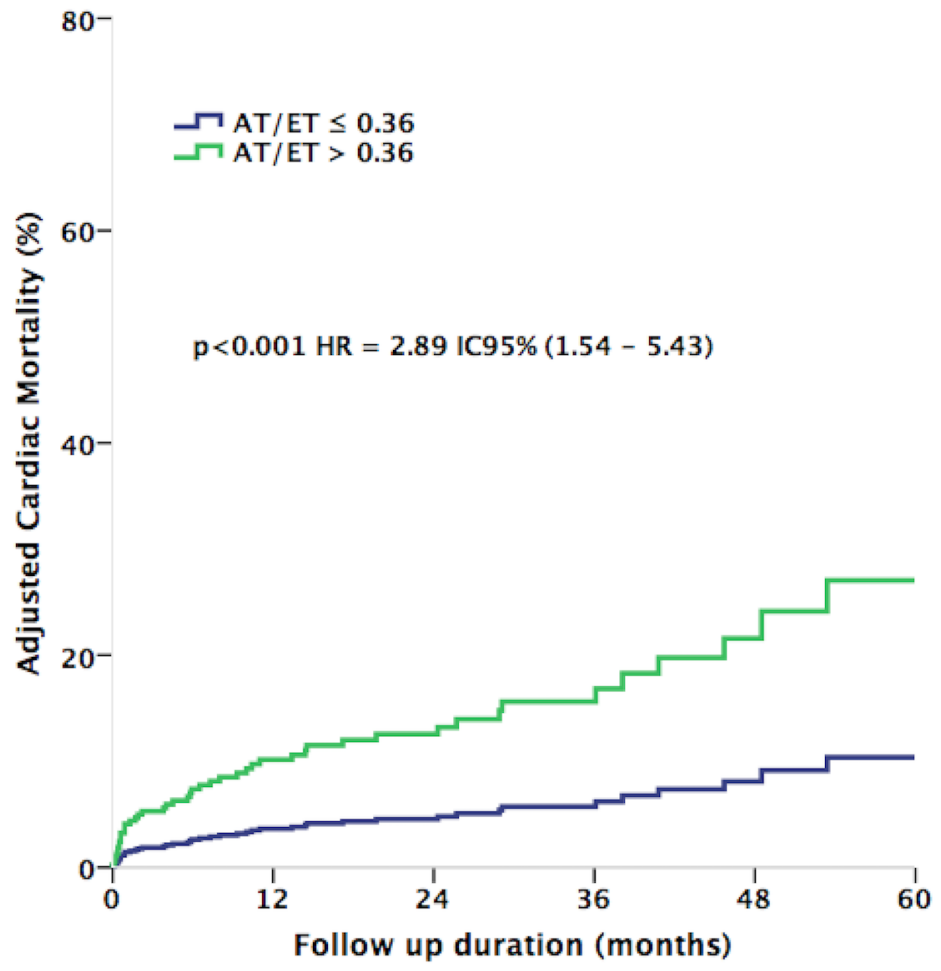




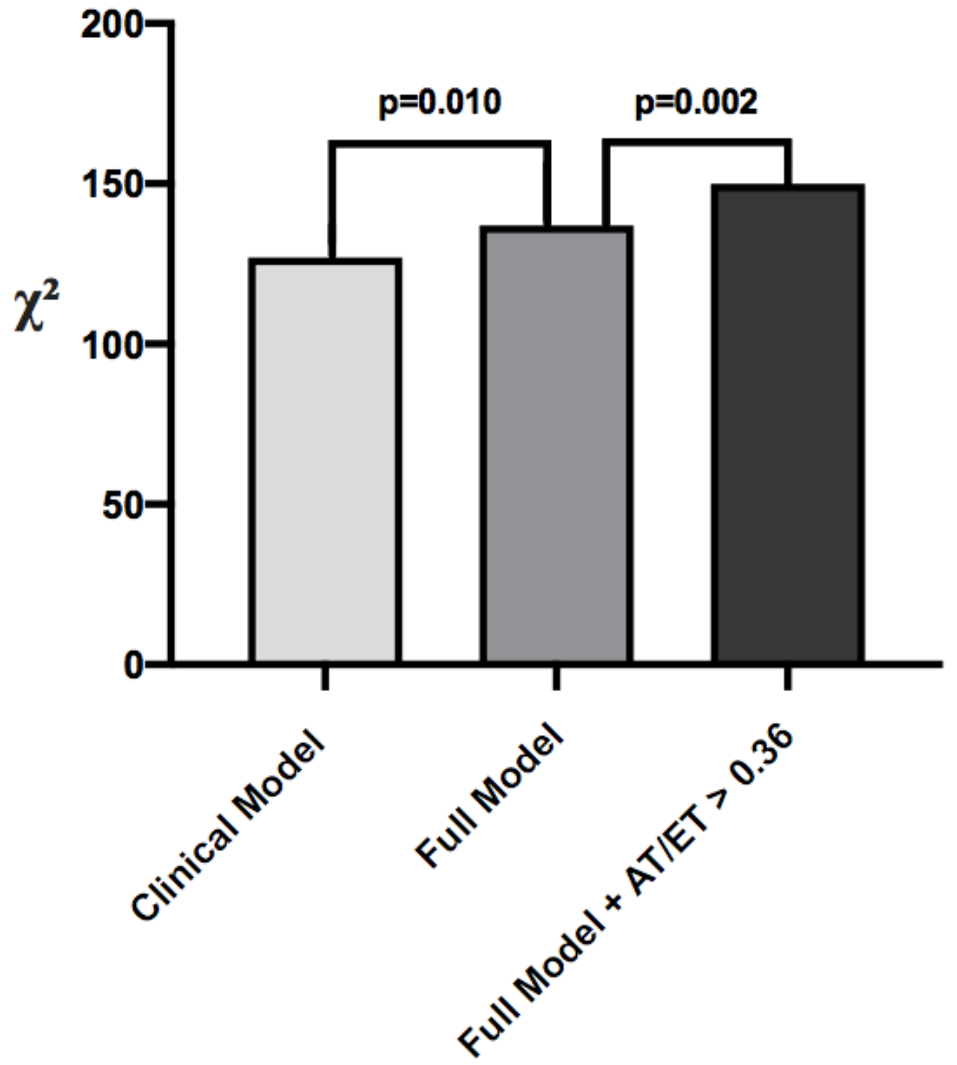


HR (95\% Cl), P

$P$ for interaction 
Table 1. Baseline demographic and clinical characteristics of the study patients with low gradient severe aortic stenosis according to AT/ET threshold $\leq$ or $>0.36$

\begin{tabular}{lcccc}
\hline \multicolumn{1}{c}{ Variable } & \multicolumn{4}{c}{ AT/ET threshold } \\
\hline & All & $\leq 0.36$ & $>0.36$ & P-value \\
\hline Age (years) & $(\mathrm{N}=356)$ & $(\mathrm{N}=281)$ & $(\mathrm{N}=75)$ & \\
Women & $81.0[74.8 ; 87.0]$ & $81.0[74.0 ; 87.0]$ & $83.0[76.5 ; 87.0]$ & 0.397 \\
Body mass index $\left(\mathrm{kg} / \mathrm{m}^{2}\right)$ & $206(58 \%)$ & $168(60 \%)$ & $38(51 \%)$ & 0.197 \\
Body surface area $\left(\mathrm{kg} / \mathrm{m}^{2}\right)$ & $27.3[24.2 ; 31.7]$ & $27.5[24.1 ; 32.3]$ & $26.9[24.2 ; 29.4]$ & 0.318 \\
Systolic blood pressure $(\mathrm{mm} \mathrm{Hg})$ & $1.85[1.69 ; 2.00]$ & $1.85[1.68 ; 2.02]$ & $1.84[1.73 ; 1.95]$ & 0.737 \\
Diastolic Blood Pressure $(\mathrm{mm} \mathrm{Hg})$ & $140[121 ; 150]$ & $140[123 ; 150]$ & $130[120 ; 149]$ & 0.098 \\
Heart rate (beats/min) & $73.0[61.0 ; 80.0]$ & $75.5[62.2 ; 80.0]$ & $70.0[60.0 ; 80.0]$ & 0.332 \\
Aortic Stenosis-related symptoms & $75.0[66.0 ; 87.0]$ & $74.0[65.0 ; 86.0]$ & $75.0[68.0 ; 87.0]$ & 0.553 \\
History of hypertension & $103(31 \%)$ & $75(28 \%)$ & $28(38 \%)$ & 0.136 \\
Diabetes mellitus & $268(75 \%)$ & $213(76 \%)$ & $55(73 \%)$ & 0.772 \\
Dyslipidemia & $130(36 \%)$ & $107(38 \%)$ & $23(31 \%)$ & 0.294 \\
Documented coronary artery disease & $112(31.5 \%)$ & $81(29 \%)$ & $37(49 \%)$ & 0.546 \\
History of atrial fibrillation & $128(36.0 \%)$ & $101(36 \%)$ & $27(36 \%)$ & 0.053 \\
Charlson comorbidity index & $2.00[1.00 ; 3.00]$ & $2.00[1.00 ; 3.00]$ & $2.00[1.00 ; 3.00]$ & 0.926 \\
\hline
\end{tabular}

Data are expressed as median (IQR) or number (percentage).

Dyslipidemia was considered in case of hypercholesterolemia (defined as cholesterol level greater than 200 $\mathrm{mg} / \mathrm{dL}$ and/or LDL-C level greater than $100 \mathrm{mg} / \mathrm{dL}$ ), hypertriglyceridemia (triglyceride level greater than 150 $\mathrm{mg} / \mathrm{dL}$ ) or in case of hypolipidemic treatment 
Table 2. Echocardiographic characteristics of the study patients with low gradient AS according to AT/ET threshold of 0.36

\begin{tabular}{|c|c|c|c|c|}
\hline \multirow[t]{2}{*}{ Variable } & \multicolumn{4}{|c|}{ AT/ET threshold } \\
\hline & All & $\leq 0.36$ & $>0.36$ & $\mathrm{P}$-value \\
\hline & $(\mathrm{N}=356)$ & $(\mathrm{N}=281)$ & $(\mathrm{N}=75)$ & \\
\hline \multicolumn{5}{|l|}{ Aortic valve } \\
\hline Indexed aortic valve area $\left(\mathrm{cm}^{2} / \mathrm{m}^{2}\right)$ & $0.50[0.44 ; 0.56]$ & $0.51[0.45 ; 0.57]$ & $0.47[0.42 ; 0.54]$ & 0.010 \\
\hline Aortic valve area $\left(\mathrm{cm}^{2}\right)$ & $0.93[0.79 ; 1.04]$ & $0.94[0.81 ; 1.05]$ & $0.88[0.73 ; 1.00]$ & 0.023 \\
\hline Peak aortic jet velocity $(\mathrm{m} / \mathrm{sec})$ & $3.34[3.00 ; 3.75]$ & $3.29[2.90 ; 3.68]$ & $3.70[3.30 ; 3.90]$ & $<0.001$ \\
\hline $\begin{array}{l}\text { Transaortic mean pressure } \\
\text { gradient }(\mathrm{mm} \mathrm{Hg})\end{array}$ & $27.0[21.0 ; 34.0]$ & $26.0[20.0 ; 33.0]$ & $34.0[26.5 ; 37.0]$ & $<0.001$ \\
\hline Acceleration time (AT) (msec) & $97.0[80.0 ; 109]$ & $90.0[80.0 ; 100]$ & $114[107 ; 126]$ & $<0.001$ \\
\hline Ejection time (ET) (msec) & $300[274 ; 321]$ & $300[275 ; 326]$ & $299[270 ; 320]$ & 0.428 \\
\hline $\mathrm{AT} / \mathrm{ET}$ ratio & $0.32[0.29 ; 0.36]$ & $0.30[0.28 ; 0.34]$ & $0.38[0.37 ; 0.40]$ & By design \\
\hline \multicolumn{5}{|l|}{$\begin{array}{l}\text { Cardiac output and LV } \\
\text { function }\end{array}$} \\
\hline $\begin{array}{l}\text { Left ventricular ejection fraction } \\
(\%)\end{array}$ & $61.0[55.0 ; 65.0]$ & $61.0[55.0 ; 65.0]$ & $61.0[55.0 ; 65.0]$ & 0.628 \\
\hline $\begin{array}{l}\text { Left ventricular stroke volume } \\
\text { index }\left(\mathrm{mL} / \mathrm{m}^{2}\right)\end{array}$ & $36.6[31.0 ; 43.0]$ & $36.4[30.9 ; 42.5]$ & $37.5[32.1 ; 47.4]$ & 0.182 \\
\hline $\begin{array}{l}\text { Left ventricular stroke volume } \\
\text { index }<35 \mathrm{~mL} / \mathrm{m}^{2}\end{array}$ & $148(42.2 \%)$ & $121(43.5 \%)$ & $27(37.0 \%)$ & 0.382 \\
\hline Left ventricular mass index $\left(\mathrm{g} / \mathrm{m}^{2}\right)$ & 107 [90.0;129] & $104[87.0 ; 128]$ & $114[93.0 ; 140]$ & 0.027 \\
\hline Relative wall thickness & $0.52[0.43 ; 0.61]$ & $0.52[0.43 ; 0.61]$ & $0.51[0.43 ; 0.61]$ & 0.769 \\
\hline $\begin{array}{l}\text { Left ventricular end-diastolic } \\
\text { diameter }(\mathrm{mm})\end{array}$ & $45.0[41.0 ; 50.0]$ & $45.0[41.0 ; 50.0]$ & $46.0[42.0 ; 50.0]$ & 0.517 \\
\hline $\begin{array}{l}\text { Left ventricular end-diastolic } \\
\text { volume }(\mathrm{mL})\end{array}$ & $99.5[81.2 ; 124]$ & $97.5[82.0 ; 122]$ & $110[80.8 ; 135]$ & 0.185 \\
\hline \multicolumn{5}{|l|}{ Other parameters } \\
\hline Left atrial volume index $\left(\mathrm{mL} / \mathrm{m}^{2}\right)$ & $44.0[34.0 ; 58.0]$ & $44.0[33.3 ; 57.1]$ & $45.0[35.9 ; 59.0]$ & 0.419 \\
\hline $\begin{array}{l}\text { Right ventricular systolic peak } \\
\text { pressure }(\mathrm{mm} \mathrm{Hg})^{*}\end{array}$ & 30.0 [25.0;40.0] & $30.0[25.0 ; 40.0]$ & $30.5[25.0 ; 37.0]$ & 0.829 \\
\hline
\end{tabular}

Data are expressed as median (IQR) or number (percentage).

*: data available in $269(76 \%)$ patients 
Table 3. Results of Cox multivariate analysis: relationship between AT/ET ratio > 0.36 and all-cause and cardiac mortality.

\begin{tabular}{|c|c|c|c|c|c|}
\hline & & \multicolumn{2}{|c|}{ All-cause mortality } & \multicolumn{2}{|c|}{ Cardiac mortality } \\
\hline \multirow{13}{*}{$\begin{array}{l}\text { Multivariate } \\
\text { analysis }\end{array}$} & & $\begin{array}{c}\text { Adjusted HR (CI } \\
95 \%)\end{array}$ & $\mathrm{p}$ & $\begin{array}{c}\text { Adjusted HR (CI } \\
95 \%)\end{array}$ & $\mathrm{p}$ \\
\hline & $\mathrm{AT} / \mathrm{ET}>0.36$ & $2.04(1.32,3.13)$ & 0.001 & $2.89(1.54,5.43)$ & $<0.001$ \\
\hline & Age & $1.04(1.02,1.07)$ & 0.001 & $1.03(0.99,1.07)$ & 0.195 \\
\hline & $\begin{array}{l}\text { Aortic valve } \\
\text { replacement }\end{array}$ & $0.21(0.12,0.36)$ & $<0.001$ & $0.44(0.21,0.9)$ & 0.025 \\
\hline & Male gender & $0.99(0.63,1.54)$ & 0.953 & $1.51(0.73,3.12)$ & 0.271 \\
\hline & Hypertension & $1.09(0.69,1.71)$ & 0.722 & $1.36(0.64,2.88)$ & 0.428 \\
\hline & $\begin{array}{l}\text { Documented coronary } \\
\text { artery disease }\end{array}$ & $0.71(0.47,1.06)$ & 0.09 & $0.51(0.26,1)$ & 0.050 \\
\hline & $\begin{array}{l}\text { Charlson comorbidity } \\
\text { index }\end{array}$ & $1.15(1.06,1.25)$ & $<0.001$ & $1.07(0.94,1.23)$ & 0.305 \\
\hline & Atrial fibrillation & $1.47(1.01,2.13)$ & 0.045 & $2.18(1.17,4.06)$ & 0.014 \\
\hline & $\begin{array}{l}\text { Aortic Stenosis-related } \\
\text { symptoms }\end{array}$ & $0.99(0.67,1.48)$ & 0.990 & $1.04(0.57,1.92)$ & 0.89 \\
\hline & $\begin{array}{l}\text { Left ventricular ejection } \\
\text { fraction }\end{array}$ & $0.99(0.96,1.01)$ & 0.322 & $0.99(0.95,1.03)$ & 0.494 \\
\hline & $\begin{array}{l}\text { Stroke Volume } \\
\text { index }<35 \mathrm{~mL} / \mathrm{m}^{2}\end{array}$ & $1.43(0.96,2.13)$ & 0.077 & $0.97(0.49,1.92)$ & 0.936 \\
\hline & $\begin{array}{l}\text { Aortic valve area (per } \\
0.1 \mathrm{~cm}^{2} \text { increment) }\end{array}$ & $0.89(0.79,1)$ & 0.053 & $0.8(0.66,0.98)$ & 0.027 \\
\hline
\end{tabular}

